\title{
Conjugated Zwitterionic Polyelectrolyte as the Charge Injection Layer for High-Performance Polymer Light-Emitting Diodes
}

\author{
Junfeng Fang, ${ }^{\dagger}$ Bodo H. Wallikewitz, ${ }^{\ddagger}$ Feng Gao, ${ }^{\ddagger}$ Guoli Tu, ${ }^{+, \$}$ Christian Müller, $^{\dagger}$ \\ Giuseppina Pace, ${ }^{\ddagger}$ Richard H. Friend, ${ }^{*, \neq}$ and Wilhelm T. S. Huck ${ }^{*,+,}$ \\ ${ }^{\dagger}$ Melville Laboratory for Polymer Synthesis, Department of Chemistry, University of Cambridge, Lensfield Road, \\ Cambridge CB2 1EW, U.K. \\ ${ }^{\ddagger}$ Cavendish Laboratory, Department of Physics, University of Cambridge, J. J. Thomson Avenue, Cambridge CB3 0HE, U.K. \\ ${ }^{\mathbb{S}}$ Wuhan National Laboratory for Optoelectronics, Huazhong University of Science and Technology, Wuhan 430074, China \\ "Institute for Molecules and Materials, Radboud University Nijmegen, Heyendaalseweg 135, 6525 AJ Nijmegen, The Netherlands
}

Supporting Information

ABSTRACT: A new zwitterionic conjugated polyelectrolyte without free counterions has been used as an electron injection material in polymer light-emitting diodes. Both the efficiency and maximum brightness were considerably improved in comparison with standard Ca cathode devices. The devices showed very fast response times, indicating that the improved performance is, in addition to hole blocking, due to dipoles at the cathode interface, which facilitate electron injection.

$\mathrm{C}$ onjugated polyelectrolytes (CPEs) have attracted significant attention as active materials in polymer optoelectronic devices, $^{1-5}$ especially because of their use as effective electron injection/transport layers. ${ }^{6-12}$ A range of CPEs with different counterions (anion/cation) and backbones ${ }^{13,14}$ have been synthesized in attempts to understand the role of the ions in the charge injection process. ${ }^{15,16}$ The promising electronic properties of CPEs in combination with their solubility in polar solvents offer a unique route to the realization of high-performance polymer light-emitting diodes (PLEDs) without the use of reactive Ca or Ba cathodes.

All CPEs reported to date combine charged side chains with mobile counterions such as $\mathrm{Na}^{+}, \mathrm{Br}^{-}$, and tetrasubstituted borates such as $\mathrm{BPh}_{4}^{-}$and $\mathrm{BIm}_{4}{ }^{-},{ }^{10,17-19}$ which can migrate during device operation and lead to long turn-on times and redistribution of the internal field. ${ }^{16}$ These mobile ions make the device operation mechanism more complicated, not only because they could alter the work function of the cathode $e^{10,15}$ but also because ions also have an impact on the luminescence of the light-emitting layer, ${ }^{20}$ and they introduce some of the doping characteristics of polymer light-emitting electrochemical cells (PLECs). ${ }^{5,21,22}$ Here we introduce CPEs containing zwitterionic side chains and no free counterions. These new CPEs have superior electron injection characteristics and outperform Ca electrodes.

Neutral tertiary amine polymers were synthesized by standard Pd-mediated Suzuki condensation polymerization of 2,7-bis(1,3,2-dioxaborolan-2-yl)-9,9-dioctylfluorene with 2,7-dibromo-9, 9-bis( ( N,N-dimethylamino)ethanyl)fluorene, as reported previously. ${ }^{3}$ The neutral polymer was soluble in common organic solvents such as chloroform, tetrahydrofuran (THF), and toluene but insoluble in methanol, dimethyl sulfoxide (DMSO), and water. After quaternization of the neutral polymer using 1,4-butane sultone in a THF/methanol solvent mixture, the resulting polymer, $\mathrm{F}\left(\mathrm{NSO}_{3}\right)_{2}$, was soluble in methanol and DMSO. Elemental analysis indicated near $100 \%$ conversion of the tertiary amines into sulfobetaine zwitterionic groups.

The zwitterionic polymer was then tested as an electron injection layer by spin-coating 2-10 $\mathrm{nm}$ thick films [as determined by UVabsorbance; see the Supporting Information (SI)] on top of a $100 \mathrm{~nm}$ thick layer of poly $\left(9,9^{\prime}\right.$-dioctylfluorene-co-benzothiadiazole) (F8BT), which acted as the light-emitting layer (Scheme 1). The luminance $(L)$-versus-voltage $(V)$ and current efficiency-versus- $V$ characteristics of devices containing $2 \mathrm{~nm}$ thick $\mathrm{F}\left(\mathrm{NSO}_{3}\right)_{2}$ layers are shown in Figure 1. The turn-on voltage (the voltage at which the brightness reached $1 \mathrm{~cd} / \mathrm{m}^{2}$ ) was $2.3 \mathrm{~V}$; the brightness increased to $1900 \mathrm{~cd} / \mathrm{m}^{2}$ at $3 \mathrm{~V}$ and reached a maximum of $\sim 80000 \mathrm{~cd} / \mathrm{m}^{2}$ at $5.8 \mathrm{~V}$. The corresponding current density and current efficiency at $5.8 \mathrm{~V}$ were $910.5 \mathrm{~mA} / \mathrm{cm}^{2}$ and $8.8 \mathrm{~cd} / \mathrm{A}$, respectively (red $O$ ). The maximum efficiency was $10.4 \mathrm{~cd} / \mathrm{A}$ at $4.4 \mathrm{~V}$ with a brightness of $26000 \mathrm{~cd} / \mathrm{m}^{2}$. Importantly, the device efficiency (Figure $1 \mathrm{~b}$ ) was stable at different operating voltages, and no significant decrease was observed up to $5.8 \mathrm{~V}$.

For comparison with the properties of the zwitterionic CPE, we fabricated $\mathrm{Ca} / \mathrm{Al}$ (green $\boldsymbol{\Delta}$ ) and $\mathrm{Al}$-only (black $\square$ ) devices under the same conditions (Figure 1). As expected, the Al-only device showed very poor device performance due to poor electron injection (see the SI). The $\mathrm{Ca} / \mathrm{Al}$ devices showed much better device performance because of improved electron injection resulting from the small difference between the LUMO energy of F8BT $(2.94 \mathrm{eV})$ and the work function of $\mathrm{Ca}(2.87 \mathrm{eV})$. These devices had the same turn-on voltage as the $\mathrm{F}\left(\mathrm{NSO}_{3}\right)_{2}$-based devices, but the maximum brightness reached only $30000 \mathrm{~cd} / \mathrm{m}^{2}$, which was much lower than that of the $\mathrm{F}\left(\mathrm{NSO}_{3}\right)_{2}$-based devices $\left(80000 \mathrm{~cd} / \mathrm{m}^{2}\right)$; the efficiency of the devices was also approximately halved at all operating voltages.

The film absorption and photoluminescence (PL) measurements (see the SI) showed similar properties for the zwitterionic and neutral polymers. Minor differences included a red shift of $\sim 3 \mathrm{~nm}$

Received: September 22, 2010

Published: December 20, 2010 
Scheme 1. Synthesis and Structure of the Zwitterionic CPE

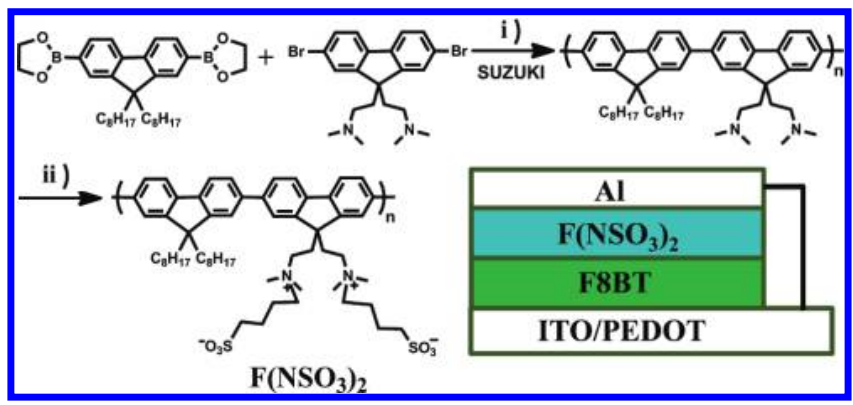

${ }^{a}$ Conditions: (i) $\mathrm{Pd}\left(\mathrm{PPh}_{3}\right)_{4}, 2 \mathrm{M} \mathrm{K}_{2} \mathrm{CO}_{3}$, toluene, reflux, 3 days; (ii) $\mathrm{THF} /$ methanol, 1,4-butane sultone, $70^{\circ} \mathrm{C}, 3$ days.

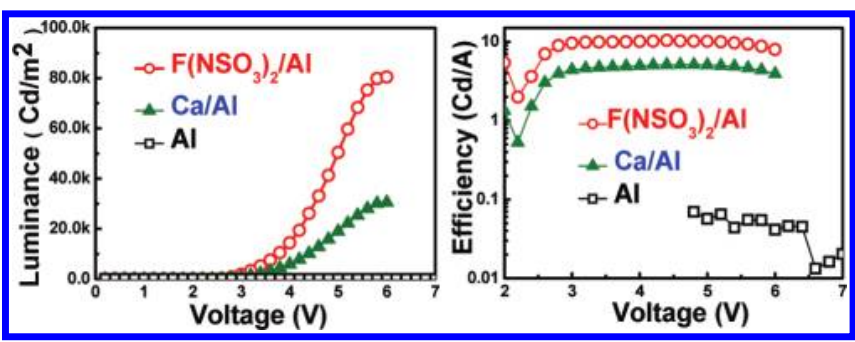

Figure 1. (a) $L-V$ and (b) current efficiency-vs- $V$ characteristics of PLEDs with the following device structures: ITO/PEDOT:PSS/F8BT/ $\mathrm{F}\left(\mathrm{NSO}_{3}\right)_{2} / \mathrm{Al}$ (red O); ITO/PEDOT:PSS/F8BT/Ca/Al (green $\mathbf{\Delta}$ ); ITO/PEDOT:PSS/F8BT/Al (black $\square$ ).

for $\mathrm{F}\left(\mathrm{NSO}_{3}\right)_{2}$ in both the UV and PL spectra. This strongly suggests that the electronic properties of $\mathrm{F}\left(\mathrm{NSO}_{3}\right)_{2}$ are not affected by the strong dipole of the zwitterionic side group. The energy of the HOMO in both the neutral precursor polymer and $\mathrm{F}\left(\mathrm{NSO}_{3}\right)_{2}$ was $5.6 \mathrm{eV}$, as determined by cyclic voltammetry; the corresponding LUMO energies were calculated through the absorption onset at 2.6 and $2.7 \mathrm{eV}$, respectively. Since the LUMO of F8BT lies at $2.9 \mathrm{eV}$ and the work function of $\mathrm{Al}$ is $4.3 \mathrm{eV}$, it is clear that the insertion of the $\mathrm{F}\left(\mathrm{NSO}_{3}\right)_{2}$ layer should, if anything, reduce the electron injection barrier from $\mathrm{Al}$ to $\mathrm{F} 8 \mathrm{BT}$.

Introducing ionic charges into the electron injection layer generally leads to long response times due to charge motion. ${ }^{16}$ Figure 2 shows the device response times for the zwitterionic CPEs at $4.9 \mathrm{~V}$, which were measured by applying a rectangular voltage pulse with a duration of $750 \mathrm{~ms}$. The devices showed very short response times $(\sim 10 \mu \mathrm{s}$; Figure 2$)$. This is the shortest response time reported for organic light-emitting diodes (OLEDs) with CPE injection layers ${ }^{8}$ and is comparable to the response times of OLEDs with metal electrodes. ${ }^{23-25}$

The short response times strongly indicate that long-range ion motion does not play a major role in the charge injection process. Because the dipoles are fixed to the polymer backbone, long distance motion is prevented, but reorientation in the electric field occurs in response to an applied electric field above a threshold of $\sim 3 \times$ $10^{5} \mathrm{~V} / \mathrm{cm}$ (3 V; Figure 3). This produces a displacement charge of the reoriented dipoles in addition to the capacitive charging during switch-on. The displacement charge was visible as a slow current decay from $\sim 200 \mathrm{~ns}$ to $\sim 2 \mu$ s following the capacitive charging peak at the beginning of the current pulse (Figure 2). The sum of the displacement and capacitive charging of devices with the $\mathrm{F}\left(\mathrm{NSO}_{3}\right)_{2}$ layer reached up to double the value for pure capacitive charging, depending on the $\mathrm{F}\left(\mathrm{NSO}_{3}\right)_{2}$ layer thickness

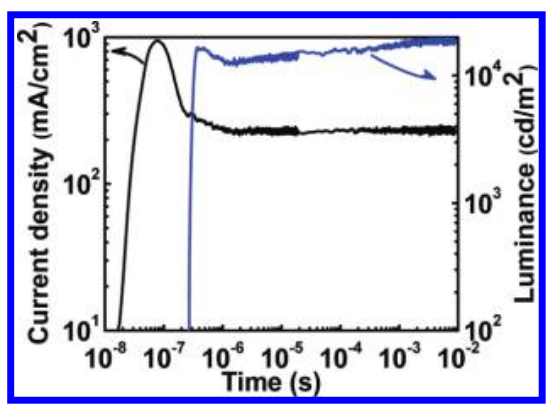

Figure 2. Brightness (blue line) and current density (black line) dynamics of ITO/PEDOT:PSS/F8BT/F $\left(\mathrm{NSO}_{3}\right)_{2}(7 \mathrm{~nm}) / \mathrm{Al}$ device using rectangular voltage pulses of $4.9 \mathrm{~V}$ at a frequency of $1 \mathrm{~Hz}$.

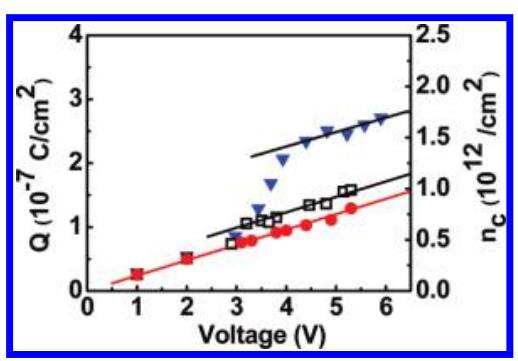

Figure 3. Capacitive charge $(Q)$ and charge density $\left(n_{\mathrm{c}}\right)$ calculated (line, $\varepsilon=3$ ) and measured for an ITO/PEDOT:PSS/F8BT/Ca/Al device (red ) as well as the sum of displacement charge and capacitive charge from ITO/PEDOT:PSS/F8BT/F $\left(\mathrm{NSO}_{3}\right)_{2} / \mathrm{Al}$ with a $7 \mathrm{~nm}$ (black $\square$ ) or $12 \mathrm{~nm}$ (blue $\boldsymbol{\nabla}) \mathrm{F}\left(\mathrm{NSO}_{3}\right)_{2}$ layer. Thin black lines are guides for the eye.

(Figure 3). Pure capacitive charging was measured from ITO/ PEDOT:PSS/F8BT/Ca/Al devices and was in agreement with calculations using standard equations for capacitance. After orientation of the dipoles in the field, the charging of devices with $\mathrm{F}\left(\mathrm{NSO}_{3}\right)_{2}$ layers followed the trend for pure capacitive charging (thin black line, Figure 3 ). It is noteworthy that the light turn-on was delayed for $\sim 300 \mathrm{~ns}$ after the current turn-on, as the electroluminescence $(\mathrm{EL})$ was rising while the displacement charge was building up after the end of capacitive charging (Figure 2).

Improved injection by the oriented zwitterionic CPE layer was also obvious from dc current density-versus-voltage measurements (see the $\mathrm{SI}$ ), as the current for the $\mathrm{F}\left(\mathrm{NSO}_{3}\right)_{2}$-based device was $\sim 1.35$-fold higher than that for the device with $\mathrm{Ca} / \mathrm{Al}$ cathodes above $3.5 \mathrm{~V}$. In a previous publication, Kabra et al. ${ }^{27}$ showed that the electron current is $\sim 3$ orders of magnitude higher than the hole current in ITO/PEDOT:PSS/F8BT/Ca/Al devices as a result of a low electron injection barrier and thus bulk-limited electron transport. This points to electron-dominated current in ITO/PEDOT:PSS/F8BT/F $\left(\mathrm{NSO}_{3}\right)_{2} / \mathrm{Al}$ devices as well. Additionally, the CPE layer works as a hole-blocking layer because the low-lying $(5.6 \mathrm{eV}) \mathrm{HOMO}$ impedes hole extraction, thus enhancing the recombination probability of holes and electrons to form emissive excitons. In combination with the exclusion of the quenching $\mathrm{Ca}$ electrode and its substitution with the transparent $\mathrm{F}\left(\mathrm{NSO}_{3}\right)_{2}$ spacer in front of the highly reflective $\mathrm{Al}$ electrode, an increase in brightness by a factor of $\sim 2.7$ is achieved. These effects result in a factor of $\sim 2$ increase in efficiency relative to devices with $\mathrm{Ca} / \mathrm{Al}$ electrodes. Improved injection by permanent dipoles is in line with recent findings from the Bazan group on small-molecule zwitterionic injection layers. $^{28}$ 
Huang et al. ${ }^{11}$ found that a neutral polymer with a hydroxyl group showed good charge injection properties, which were attributed to doping induced by the reaction between $\mathrm{Al}$ and hydroxyl groups on the polymers or the dipole formed between the polymer and the electrodes. ${ }^{11,26}$ Here there is no obvious chemical reaction between the charged polymer and $\mathrm{Al}$, so the presence of the dipole must be the main contributing factor. Further details of the injection mechanism, including the influence of the thickness and morphology of the CPE layer, ${ }^{29}$ and the dependence of the rise time on the applied voltage are under investigation and beyond the scope of this paper. However, the short EL response time is a clear advantage over conjugated polyelectrolytes with free counterions, which exhibit rise times in the range of milliseconds or seconds.

In summary, we have synthesized a new zwitterionic polyelectrolyte without free counterions and used it as an electron injection material in PLEDs. The device performance of the $\mathrm{F}\left(\mathrm{NSO}_{3}\right)_{2}$ based devices measured at either maximum brightness or current efficiency was over 2 times higher than that of Ca-based devices at all operating voltages. The improved performance is due to the improvement of electron injection, which leads to higher electron currents. In combination with impeded hole extraction, an increase in brightness and thus an increase in efficiency by a factor of $\sim 2$ has been achieved. More importantly, the devices show very short response times (less than $\sim 10 \mu \mathrm{s}$ ), which indicates that the fixed charges prevent movement of ions and instead present strong dipoles near the cathodes, which facilitate charge injection.

\section{ASSOCIATED CONTENT}

S Supporting Information. Synthesis of $\mathrm{F}\left(\mathrm{NSO}_{3}\right)_{2}$, device fabrication procedures, and device characteristics. This material is available free of charge via the Internet at http://pubs.acs.org.

\section{AUTHOR INFORMATION}

\section{Corresponding Author}

rhf10@cam.ac.uk; wtsh2@cam.ac.uk

\section{ACKNOWLEDGMENT}

This work was partly funded by the EPSRC Nanotechnology Grand Challenges: Energy Programme (EP/F056702/1) and Basic Technology Research Grant Initiative COSMOS (EP/ D04894X/1).

\section{REFERENCES}

(1) Ferreira, M.; Rubner, M. F. Macromolecules 1995, 28, 7107-7114.

(2) Huang, F.; Hou, L. T.; Wu, H. B.; Wang, X. H.; Shen, H. L.; Cao, W.; Yang, W.; Cao, Y. I. Am. Chem. Soc. 2004, 126, 9845-9853.

(3) Wallikewitz, B. H.; de la Rosa, M.; Kremer, J. H.-W. M.; Hertel, D.; Meerholz, K. Adv. Mater. 2010, 22, 531-534.

(4) Ma, W. L.; Iyer, P. K.; Gong, X.; Liu, B.; Moses, D.; Bazan, G. C.; Heeger, A. I. Adv. Mater. 2005, 17, 274-277.

(5) Pei, Q. B.; Yu, G.; Zhang, C.; Yang, Y.; Heeger, A. J. Science 1995, 269, 1086-1088.

(6) Cimrova, V.; Schmidt, W.; Rulkens, R.; Schulze, M.; Meyer, W.; Neher, D. Adv. Mater. 1996, 8, 585-588.

(7) Wu, H. B.; Huang, F.; Mo, Y. Q.; Yang, W.; Wang, D. L.; Peng, J. B.; Cao, Y. Adv. Mater. 2004, 16, 1826-1830.

(8) Hoven, C. V.; Garcia, A.; Bazan, G. C.; Nguyen, T. Q. Adv. Mater. 2008, 20, 3793-3810.
(9) Hoven, C. V.; Yang, R. Q.; Garcia, A.; Crockett, V.; Heeger, A. J.; Bazan, G. C.; Nguyen, T. Q. Proc. Natl. Acad. Sci. U.S.A. 2008, 105, $12730-12735$.

(10) Yang, R. Q.; Xu, Y. H.; Dang, X. D.; Nguyen, T. Q.; Cao, Y.; Bazan, G. C. I. Am. Chem. Soc. 2008, 130, 3282-3283.

(11) Huang, F.; Niu, Y. H.; Zhang, Y.; Ka, J. W.; Liu, M. S.; Jen, A. K. Y. Adv. Mater. 2007, 19, 2010-2014.

(12) Gong, X.; Wang, S.; Moses, D.; Bazan, G. C.; Heeger, A. J. Adv. Mater. 2005, 17, 2053-2058.

(13) Wang, L.; Liang, B.; Huang, F.; Peng, J. B.; Cao, Y. Appl. Phys. Lett. 2006, 89, No. 151115.

(14) Yang, R. Q.; Wu, H. B.; Cao, Y.; Bazan, G. C. J. Am. Chem. Soc. 2006, 128, 14422-14423.

(15) Wu, H. B.; Huang, F.; Peng, J. B.; Cao, Y. Org. Electron. 2005, 6, $118-128$.

(16) Hoven, C.; Yang, R.; Garcia, A.; Heeger, A. J.; Nguyen, T. Q.; Bazan, G. C. I. Am. Chem. Soc. 2007, 129, 10976-10977.

(17) Seo, J. H.; Yang, R. Q.; Brzezinski, J. Z.; Walker, B.; Bazan, G. C.; Nguyen, T. Q. Adv. Mater. 2009, 21, 1006-1011.

(18) Oh, S. H.; Vak, D.; Na, S. I.; Lee, T. W.; Kim, D. Y. Adv. Mater. 2008, 20, 1624-1629.

(19) Garcia, A.; Yang, R.; Jin, Y.; Walker, B.; Nguyen, T. Q. Appl. Phys. Lett. 2007, 91, No. 153502.

(20) Hodgkiss, J. M.; Tu, G. L.; Albert-Seifried, S.; Huck, W. T. S.; Friend, R. H. I. Am. Chem. Soc. 2009, 131, 8913-8921.

(21) Pei, Q. B.; Yang, Y.; Yu, G.; Zhang, C.; Heeger, A. J. J. Am. Chem. Soc. 1996, 118, 3922-3929.

(22) Fang, J.; Matyba, P.; Robinson, N. D.; Edman, L. J. Am. Chem. Soc. 2008, 130, 4562-4568.

(23) Book, K.; Nikitenko, V. R.; Bassler, H.; Elschner, A. Synth. Met. 2001, 122, 135-139.

(24) Wang, J.; Sun, R. G.; Yu, G.; Heeger, A. J. Synth. Met. 2003, 137, 1009-1010.

(25) Pinner, D. J.; Friend, R. H.; Tessler, N. L. Appl. Phys. 1999, 86, $5116-5130$.

(26) Michota, A.; Kudelski, A.; Bukowska, J. Surf. Sci. 2002, 502, 214-218.

(27) Kabra, D.; Lu, L. P.; Song, M. H.; Snaith, H. J.; Friend, R. H. Adv. Mater. 2010, 22, 3194-3198.

(28) Li, H. P.; Xu, Y. H.; Hoven, C. V.; Li, C. Z.; Seo, J. H.; Bazan, G. C. I. Am. Chem. Soc. 2009, 131, 8903-8912.

(29) Chen, Z.; Dang, X.-D.; Gutacker, A.; Garcia, A.; Li, H.; Xu, Y.; Ying, L.; Nguyen, T.-Q.; Bazan, G. C. I. Am. Chem. Soc. 2010, 132, $12160-12162$. 